\title{
Proceedings
}

\section{Habits, We-Intentionality and Rituals ${ }^{+}$}

\author{
Raffaela Giovagnoli \\ Faculty of Philosophy, Pontifical Lateran University, Piazza San Giovanni in Laterano 4, \\ Vatican City, 00120 Rome, Italy; giovagnoli@pul.it \\ + Conference Morphological, Natural, Analog and Other Unconventional Forms of Computing for Cognition \\ and Intelligence (MORCOM), Berkeley, CA, USA, 2-6 June 2019. \\ Published: 7 May 2020
}

\begin{abstract}
The notion of "habit" is at the center of a lively philosophical debate that shows how some ideas from classical thought are still plausible and useful to understand human behavior in ordinary life. Following Aristotle, we can intend habits through the process of "habits learning", which is a central topic in neuroscience and neurobiology. We investigate the dimensions of habitual behavior and its extension to the social world.
\end{abstract}

Keywords: habits; we-intentionality; rituals; status function

\section{Introduction}

A habit is not only a mere automatism or a repetitive behavior, but also a stable disposition for action (practical skill), which entails the relationship between automatism and flexibility implying also control. The difference between habits and automatism or simple routines is that the former give control over actions, while the latter do not (Bernacer, Murillo, Lombo, Gimenez-Amaya). Philosophy and neurobiology can be connected by the consideration of habit as "stable disposition for self-development". The traditional sense of habit (Habitus) was introduced by Aristotle to characterize the notion of "virtue". Virtue is a habit as disposition to face good or bad emotions and tendencies. Aristotle conceived the habit also as a kind of mechanism that is analogous to the natural mechanisms and somehow guarantees the uniform repetition of facts, acts or behavior by eliminating or reducing stress and fatigue and then making them pleasant. Aquinas inherited the Aristotelian view and maintains that habit is not potency (i.e., a capacity) in that it makes us able or unable to do good or wrong. This notion of habit is defined also by Dewey, who thinks that it is a human activity that is influenced by previous activity, namely it is acquired. The habit as a repetition without reasoning is exemplarily discussed by Pascal and Hume. Bergson uses this term to describe moral obligations as social habits that promote life and the social order. Metaphysical interpretations of the notion of habit are offered by Main de Biran, Hegel and Ravaisson. In these cases we observe a deep interest in religious views. We briefly describe interesting connections between the Aristotelian perspective and neuroscience, and how to conceive the social dimension of habitual behavior.

\section{Habits between Philosophy and Neuroscience}

The explicit investigation of habits in neuroscience is quite recent even though the fact that "we act according to our habits, from the time we rise and go through our morning routines until we fall asleep after evening routines" is evident [1]. Ann Graybiel seems to establish a fruitful relationship between habits and goals. Goals are explicitly present during action evolution and selection, but they increasingly blur the more an action is repeated. She proposes examples of habits as fixed action patterns, namely complex repetitive behavior in non-human animals and repetitive behavior and thoughts in human pathological conditions. The result is that habit completely disengaged from a 
goal becomes either a stimulus-response pair for a non-human animal or a pathological trait for human beings. Habits play an important role in social life, as in this case they are "shaped" as mannerism and rituals.

James' notion of habit has strong connections with neuroscientific research namely in the study of neurobiological foundations of motor routines, the relation of consciousness with habits, the mechanism of instrumental learning in animals and the implication of these phenomena in human disorders. Nevertheless, because of the associationist view grounding these studies, it seems far from explaining the complexity of human habits. Consequently, we underscore three important results from a deep study of the Aristotelian analysis of habit in Nicomachean Ethics [2]:

1. An acquired habit is an acquired disposition to perform certain types of actions;

2. this disposition, usually acquired by means of repetition of one or more actions, makes the exception of these actions prompter, more spontaneous and autonomous from continuous supervision, all of which generally leads to a better performance; and

3. if the habit increases cognitive control of the actions, it can be termed a habit-as-learning; on the contrary, it increases their rigidity, it is a habit-as-routine.

\section{From Habits to Rituals: The Role of We-Intentionality}

Our challenge is to extend the process to the social sphere, as habits can be shared and institutionalized in the form of rituals. Habits can be viewed from an individual mode or I-mode because they are idiosyncratic as regards personal behavior. Each person has their own habits, i.e., how to perform certain actions that become daily routines and the meaning associated with them. Habits have a very important function in individual life because they reduce the complexity of daily life; they simply make our daily life easier and pleasant. Rituals can be seen as habits in a We-mode, they present the dimension of routine but also the active stable disposition for action, which shows how rituals play a fundamental role in individual and social life.

Anthropology, ethnology, sociology and social psychology traditionally investigate them. We use the word "rite" or "ritual", referring especially to religion and myth, to indicate that aspect of it that makes the religious experience possible in the mystical dimension. The philosophical debate on the rituals is lively and presents many different perspectives. The set of acts which characterize human habits can be institutionalized to form the cultural rituals that belong to human life-forms. Rituals are institutionalized habits in the We-Form and have important functions in our daily life. They serve to share emotions derived from different contexts of experience (experience of precariousness, danger, pain, necessity to follow cultural norms etc.) to establish institutions and to favor social order [3].

Our social world is strictly dependent on intentionality-relative functions that are characterized by two special features. They require (a) a shared intentionality, namely "collective intentionality", and (b) collective imposition and recognition of a status. The "constitutive rule" is essential to the process of the constitution of institutions in general.

The canonical form introduced by Searle $[4,5](1997,2010)$ is:

Status function $=X$ counts as $\mathrm{Y}$ in $\mathrm{C}$

For instance, a certain expression counts as a promise in a certain context, C. Therefore, it is fundamental to assign functions to objects and persons. Together with the notion of status function, there are two more basic notions that occur in explaining the successful functioning and stability of social institutions. The first is "cooperation" as a "strong" form of collective intentionality and the second is "collective recognition" as its "weak" form. We can observe that habitual behavior in the we-mode, works on a fundamental and deep level. A very famous example of description of a very important ritual is marriage, introduced by Searle. First, we need to be moved to act in a certain way. "We-Intentionality" works when we want to do something together so that we cooperate to achieve our common goal. Collective intentionality presents a weak form (collective recognition) and a strong form (cooperation). Both are crucial for the rituals, in our case marriage. Collective recognition means that the couple simply accepts the institution of marriage prior to actually getting married. The actual 
marriage ceremony is an example of active cooperation, in which the couple enters in a new social situation, consequently acquiring new social statuses through the speech act of promise. The social context requires the speech act of declaration from the part of the institutional figure who has the suitable deontic powers to celebrate the rite and to ascribe the new status to the couple. Weintentionality works when we want to do something together (we have a collective intention) so that we can cooperate to achieve our common goal. As we already saw, collective intentionality takes a weak form (collective recognition) and a strong form (cooperation). Both are crucial to create and stabilize social norms and institutions. To schematize:

(1) We have "collective recognition", which means that people simply accept the deontic dimensions that structure the relevant social situation.

(2) The actual performance of the required moves is an example of active cooperation, in which individuals enter in a new social situation, consequently acquiring new social statuses.

(3) This fact is obtained by the performance of corresponding speech acts, depending on the roles of the agents in the relevant social contexts.

Funding: This research received no external funding.

Acknowledgments: I warmly thank Terrence Deacon for his support and participation in the organization of the miniconference "Habits and Rituals". I also thank all the participants for their very interesting comments.

Conflicts of Interest: The author declares no conflict of interest.

\section{References}

1. Graybiel, A. Habits, Rituals and the Evaluative Brain. Ann. Rev. Neurosci. 2008, 31, 359-387.

2. Lombo, J.A.; Gimenez-Amaya, J.M. The unity and stability of human behavior. An interdisciplinary approach to habits between philosophy and neuroscience. Front. Hum. Neurosci. 2014, 8, 607.

3. Giovagnoli R. From Habits to We-intentionality. Rituals as Social Habits. In The Logic of Social Practices; Giovagnoli, R., Lowe, R., Eds.; Springer: Cham, Swizerland, 2020; pp. 185-199.

4. Searle, J. The Construction of Social Reality; Free Press: London, UK, 1997.

5. Searle, J. Making the Social World; OUP: Oxford, UK, 2010.

() 2020 by the authors. Licensee MDPI, Basel, Switzerland. This article is an open access article distributed under the terms and conditions of the Creative Commons Attribution (CC BY) license (http://creativecommons.org/licenses/by/4.0/). 